\title{
Algorithm for calculation of a CCGT of a trinary type with an air condenser
}

\author{
Svyatoslav Tsibulskiy ${ }^{1, *}$, Nikolay Galashov ${ }^{1}$, Denis Mel'nikov ${ }^{1}$, Alexandr Kiselev ${ }^{1}$, and \\ Al'bina Bannova ${ }^{1}$ \\ ${ }^{1}$ National Research Tomsk Polytechnic University, 634050 Tomsk, Russia
}

\begin{abstract}
In this paper, an algorithm and a program have been developed that make it possible in a complex to calculate the combined operation of a combined-cycle gas turbine (CCGT) and air condenser (AC), as a result of which it is possible to investigate their operation and performance, depending on a large number of operating parameters.
\end{abstract}

\section{Introduction}

The binary type CCGTs currently have the highest efficiency of generating electricity. The most powerful and perfect CCGT is based of GTU 9NA.02 of GE Power, the efficiency of which reached $63.7 \%$. The working body of the steam turbine unit (STU) of this CCGT is water. The ways of further increasing the efficiency of the combined-cycle plant are given in the paper [1]. This is an increase in the initial temperature of a gas turbine, a decrease in heat losses in a steam turbine cycle and a heat recovery steam generator (HRSG), lower temperature heat rejection from the cycle.

The decrease in the heat removal temperature affects the efficiency of the cycle more than the increase in the temperature of the heat supply, but in the gas turbine it is limited by the process in the gas turbine, and in the STU - by the temperature of the cooling medium and the process in the condenser. When the STU is operating on water steam, and cooling the steam in the condenser with water, the heat removal temperature in the cycle can not be lower than $15^{\circ} \mathrm{C}$. In winter, the heat removal temperature can be lowered below $15{ }^{\circ} \mathrm{C}$ if the water steam in the condenser is cooled by air, but at the same time the reliability of the installation is reduced due to the possibility of freezing of water in the condenser tubes. Reduce the temperature of heat removal in the cycle below $0{ }^{\circ} \mathrm{C}$ and reliably work when using $\mathrm{AC}$ is possible, if low-boiling substances (LBS) used as a working fluid in the medium cycle of STU [2].

At a given steam temperature before the turbine, the increase in the efficiency of the STU is possible only due to the decrease in the heat removal temperature in the cycle, therefore it is proposed in [3] to use a low-boiling substance as the working fluid of the cycle of the STU, and to remove heat from it in an air condenser. This in winter will allow to reliably remove heat in the cycle at negative temperatures and increase the efficiency of the STU and CCGT.

\footnotetext{
Corresponding author: stzibulsky@tpu.ru
} 


\section{Algorithm for calculation of a CCGT of a trinary type with an air condenser}

The algorithm is based on the calculation of the cycle diagram of CCGT of a trinary type with AC. In the CCGT, the first cycle is the Brighton cycle for the gas turbine unit (GTU), the second and third are the Rankine cycles operating on water steam and low-boiling substances (LBS). The cycle diagram of the CCGT is shown in Fig. 1.

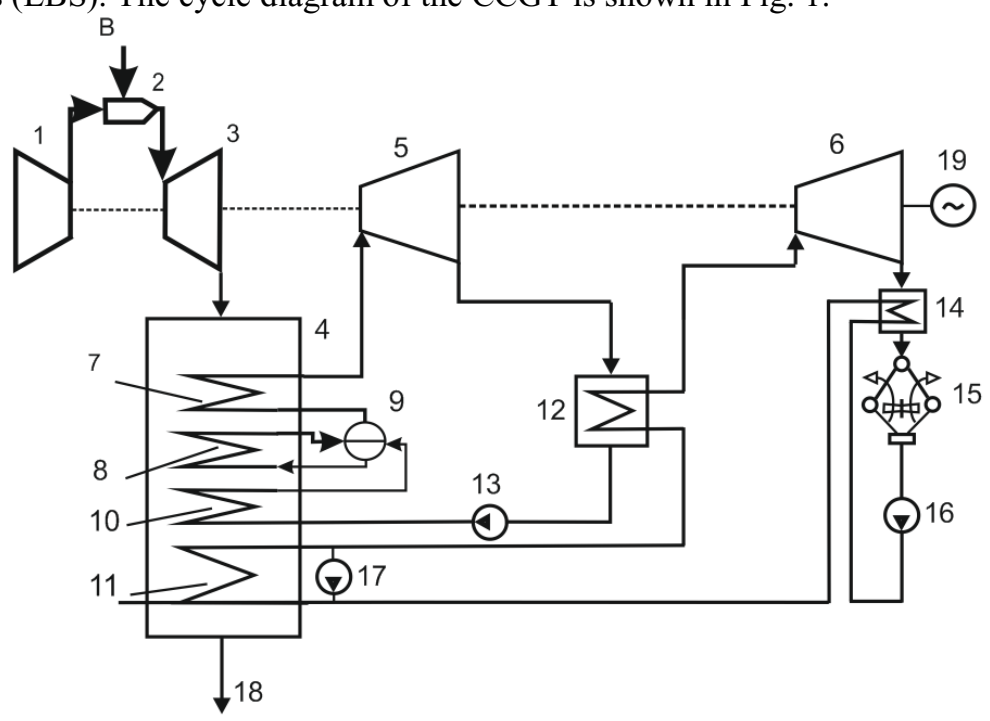

Fig. 1. The cycle diagram of the CCGT trinary type with ondensation low boiling substances in air condenser: 1-compressor; 2-the combustion chamber; 3-gas turbine; 4-HRSG; 5-high pressure cylinder (HPC); 6-low-pressure cylinder (LPC); 7-superheater; 8-evaporator; 9-boiler drum, 10high-pressure economizer, 11-low-pressure economizer; 12-condenser-evaporator; 13-condensate pump of the second cycle $\left(\mathrm{CP}_{2}\right)$; 14-steam cooler; 15-AC; 16-condensate pump of the third cycle $\left(\mathrm{CP}_{3}\right) ; 17-$-recirculation pump, 18-exhaust gases, 19-electric generator.

The initial data:

- type of GTU;

- electric power and termal efficiency GTU;

- combustible fuel composition;

- flow rate and temperature of the combustion products at the inlet to HRSG;

- pressure and temperature of water steam at the entrance to the steam turbine;

- pressure of water steam at the outlet of the steam turbine;

- type of LBS;

- cooling air temperature in the air condenser;

- the geometric characteristics of the air condenser.

For GTU, the heat input to the combustion chamber, the composition and parameters of the combustion products is determined from its initial data. The composition of the combustion products is determined by the following function:

$$
\mathrm{c}_{\mathrm{C} . \mathrm{P} .}=\mathrm{f}\left\{\mathrm{N}_{2} ; \mathrm{Ar} ; \mathrm{O}_{2} ; \mathrm{H}_{2} \mathrm{O} ; \mathrm{CO}_{2}\right\} \text {, }
$$

which depends on the nitrogen content of $\mathrm{N}_{2}$, argon Ar, oxygen $\mathrm{O}_{2}, \mathrm{H}_{2} \mathrm{O}$ steam, $\mathrm{CO}_{2}$ carbon dioxide $\mathrm{CO}_{2}$. 
The process of calculating the steam-turbine part has an iterative form [5]. For the cycle on water steam are determined the initial parameters at the outlet of the HRSG, is constructed the process of expansion in the high-pressure cylinder and is determined its power:

$$
\mathrm{N}_{\mathrm{E}}{ }^{\mathrm{HPC}}=\mathrm{D}_{0}{ }^{\mathrm{HPC}} \cdot \mathrm{H}_{\mathrm{i}}^{\mathrm{HPC}} \cdot \eta_{\mathrm{EM}} \cdot 10^{-3}, \mathrm{MW},
$$

where $\mathrm{D}_{0}{ }^{\mathrm{HPC}}$ - water steam flow rate in $\mathrm{HPC}, \mathrm{kg} / \mathrm{s}$ - for the first iteration is given an arbitrary value subsequently clarified; $\mathrm{H}_{\mathrm{i}}{ }^{\mathrm{HPC}}$ - effective heat drop in the high pressure cylinder, $\mathrm{kJ} / \mathrm{kg} ; \eta_{\mathrm{EM}}$ - electromechanical efficiency of steam-turbine plant.

The properties of the condensation of water steam and the conditions for the transfer of heat to the low-boiling matter in the condenser-evaporator are determined from the pressure at the outlet of the high-pressure cylinder. Calculate the water parameters after the condensate pump - at the inlet to the HRSG:

$$
\mathrm{h}_{\mathrm{IN}}{ }^{\mathrm{EC} 1}=\left(\mathrm{h}^{\prime}{ }_{\mathrm{W}}\right)^{\mathrm{CE}}+\Delta \mathrm{h}_{\mathrm{CP} 2}, \mathrm{~kJ} / \mathrm{kg},
$$

where $\left(\mathrm{h}^{\prime}{ }_{\mathrm{w}}\right)^{\mathrm{CE}}$ - enthalpy of water condensate in the $\mathrm{CE}, \mathrm{kJ} / \mathrm{kg} ; \Delta \mathrm{h}_{\mathrm{CP} 2}$ - increase in enthalpy in a high-pressure condensate pump, $\mathrm{kJ} / \mathrm{kg}$.

The properties of water, steam and combustion products in the waste heat boiler are calculated. Temperature and enthalpy of combustion products at the cold end of the evaporator:

$$
\begin{gathered}
\theta_{\mathrm{E}}=\mathrm{t}_{\mathrm{S}}{ }^{\mathrm{E}}+\delta \mathrm{t}_{\mathrm{E}},{ }^{\circ} \mathrm{C} ; \\
\mathrm{I}_{\mathrm{E}}=\mathrm{f}\left(\mathrm{c}_{\mathrm{C} . P .} ; \theta_{\mathrm{E}} ; \mathrm{p}_{\mathrm{C} . \mathrm{P} .}\right), \mathrm{kJ} / \mathrm{kg},
\end{gathered}
$$

where $t_{S}{ }^{\mathrm{E}}$ - saturation temperature in the evaporator, ${ }^{\circ} \mathrm{C} ; \delta \mathrm{t}_{\mathrm{E}}-$ temperature difference at a pinch-point of evaporator, ${ }^{\circ} \mathrm{C}$; $\mathrm{p}_{\text {C.P. }}-$ combustion pressure in the path of the HRSG.

The flow rate of water vapor is determined [4]:

$$
\mathrm{D}_{0}{ }^{\mathrm{HPC}}\left(\mathrm{h}_{0 \mathrm{w} . \mathrm{S} .}-\left(\mathrm{h}^{\prime}{ }_{\mathrm{W}}\right)^{\mathrm{E}}\right)=\mathrm{G}_{\mathrm{G}} \cdot\left(\mathrm{I}_{\mathrm{IN}}{ }^{\mathrm{HRSG}}-\mathrm{I}_{\mathrm{E}}\right),
$$

where $h_{0 w . s .}-$ enthalpy of water steam at the outlet of the high-pressure superheater, $\mathrm{kJ} / \mathrm{kg} ;\left(\mathrm{h}^{\prime}{ }_{\mathrm{W}}\right)^{\mathrm{E}}$ - enthalpy of water at the inlet to the evaporator, $\mathrm{kJ} / \mathrm{kg} ; \mathrm{G}_{\mathrm{G}}$ - consumption of combustion products, $\mathrm{kg} / \mathrm{s}$; $\mathrm{I}_{\mathrm{IN}}{ }^{\mathrm{HRSG}}$ - enthalpy of combustion products at the outlet from the GTU - inlet to the HRSG, $\mathrm{kJ} / \mathrm{kg}$; $\mathrm{I}_{\mathrm{E}}$ - enthalpy of combustion products at the evaporator outlet, $\mathrm{kJ} / \mathrm{kg}$.

If obtained in (1.6) flow rate of water steam has a predetermined divergence in (1.2) is more than $0.5 \%$, then the calculation is repeated by substituting found in (1.2) flow rate.

For given type of LBS and water steam property are determined properties of LBS and its flow in CE:

$$
\begin{gathered}
\left(\mathrm{t}_{\mathrm{S}}{ }^{\mathrm{LBS}}\right)^{\mathrm{CE}}=\mathrm{t}_{\mathrm{S}}{ }^{\mathrm{CE}}-\delta \mathrm{t}_{\mathrm{CE}},{ }^{\circ} \mathrm{C} ; \\
\mathrm{p}_{\mathrm{S}}{ }^{\mathrm{CE}}=\mathrm{f}\left(\mathrm{LBS} ;\left(\mathrm{t}_{\mathrm{S}}{ }^{\mathrm{LBS}}\right)^{\mathrm{CE}}\right), \mathrm{MPa} ; \\
\left(\mathrm{h}^{\prime \prime}{ }_{\mathrm{LBS}}\right)^{\mathrm{CE}}=\mathrm{f}\left(\mathrm{LBS} ; \mathrm{p}_{\mathrm{S}}{ }^{\mathrm{CE}}\right), \mathrm{kJ} / \mathrm{kg} ; \\
\mathrm{D}_{0}{ }^{\mathrm{LPC}}=\mathrm{Q}_{\mathrm{CE}} /\left(\left(\mathrm{h}^{\prime \prime}{ }_{\mathrm{LBS}}\right)^{\mathrm{CE}}-\mathrm{h}_{\mathrm{OUT}}{ }^{\mathrm{EC} 2}\right), \mathrm{kg} / \mathrm{s},
\end{gathered}
$$

where $\mathrm{ts}_{\mathrm{s}}{ }^{\mathrm{CE}}$ - saturation temperature of water vapor in condenser-evaporator, ${ }^{\circ} \mathrm{C} ; \delta \mathrm{t}_{\mathrm{CE}}-$ temperature head in condenser-evaporator, ${ }^{\circ} \mathrm{C}$, houT ${ }^{\mathrm{EC} 2}$ - enthalpy at the outlet of the low pressure economizer, in the first approximation is given an arbitrary value subsequently clarified, $\mathrm{kJ} / \mathrm{kg}$. 
The verification calculation of the air condenser is necessary for determining the condensation temperature $t_{C}{ }^{\text {LBS }}$ and electric energy consumption for the drive of the blowing fans with the cooling air parameters [6].

The condensation temperature $t_{C}{ }^{L B S}$, which is determined from the calculation of the air condenser, calculates the pressure at the end of the expansion process into the low-pressure cylinder:

$$
\mathrm{p}_{\mathrm{k}}^{\mathrm{LBS}}=\mathrm{f}\left(\mathrm{LBS} ; \mathrm{t}_{\mathrm{C}}{ }^{\mathrm{LBS}}\right), \mathrm{MPa} .
$$

Construct process LBS steam expansion in LPC:

$$
\begin{aligned}
& \mathrm{H}_{0}{ }^{\mathrm{LPC}}=\mathrm{h}_{0 \mathrm{LBS}}-\left(\mathrm{h}_{\mathrm{kt}}^{\mathrm{LPC}}\right)^{\mathrm{LBS}}, \mathrm{kJ} / \mathrm{kg} ; \\
& \mathrm{H}_{\mathrm{i}}^{\mathrm{LPC}}=\mathrm{H}_{0}{ }^{\mathrm{LPC}} \cdot \eta_{\mathrm{oi}}{ }^{\mathrm{LPC}}, \mathrm{kJ} / \mathrm{kg},
\end{aligned}
$$

where $\mathrm{h}_{0 \mathrm{LBS}}=\left(\mathrm{h}^{\prime \prime}{ }_{\mathrm{LBS}}\right)^{\mathrm{CE}}$ - the enthalpy of a LBS steam at the inlet to the LPC, $\mathrm{kJ} / \mathrm{kg}$; $\left(h_{k t}{ }^{L P C}\right)^{L B S}$ - the enthalpy of the low-boiling substance at the end of the theoretical expansion process in the low-pressure cylinder, $\mathrm{kJ} / \mathrm{kg} ; \eta_{\mathrm{oi}}{ }^{\mathrm{LPC}}$ - internal relative efficiency of the LPC.

The properties of the LBS at the outlet of the LPC are determined and a conclusion is made about the need to install a steam cooler (SC). Thermal calculation is carried out with the purpose of finding parameters of steam and condensate at the output of SC:

$$
\left.\mathrm{D}_{0}{ }^{\mathrm{LPC}} \cdot\left(\left(\mathrm{h}_{\mathrm{k}}{ }^{\mathrm{LPC}}\right)^{\mathrm{LBS}}-\mathrm{h}_{\mathrm{SC}}{ }^{\mathrm{LBS}}\right) \cdot \eta_{\mathrm{CP}}=\mathrm{D}_{0}{ }^{\mathrm{LPC}} \cdot\left(\mathrm{h}_{\mathrm{OUT}}{ }^{\mathrm{SC}}\right)^{\mathrm{LBS}}-\mathrm{h}_{\mathrm{CP} 2}\right),
$$

where $\mathrm{D}_{0}{ }^{\mathrm{LPC}}-\mathrm{LBS}$ steam consumption in $\mathrm{LPC}, \mathrm{kg} / \mathrm{s} ;\left(\mathrm{h}_{\mathrm{k}}{ }^{\mathrm{LPC}}\right)^{\mathrm{LBS}}-$ the enthalpy of the LBS at the end of the expansion process in $\mathrm{LPC}, \mathrm{kJ} / \mathrm{kg}$; $\mathrm{h}_{\mathrm{SC}}{ }^{\mathrm{LBS}}$ - enthalpy of the cooling vapor of the LBS from the $\mathrm{SC}, \mathrm{kJ} / \mathrm{kg}$; $\left(\mathrm{h}_{\mathrm{OUT}}{ }^{\mathrm{SC}}\right)^{\mathrm{LBS}}$ - enthalpy of liquid LBS from the $\mathrm{SC}, \mathrm{kJ} / \mathrm{kg}$; $\mathrm{h}_{\mathrm{CP} 2}-$ enthalpy of liquid LBS from the condensate pump of low pressure, $\mathrm{kJ} / \mathrm{kg}$.

The heat balance equation is compiled for the recycling system [7]. The heat balance determines the consumption of recycling:

$$
\mathrm{D}_{\mathrm{R}}=\mathrm{D}_{0}{ }^{\mathrm{LPC}} \cdot\left(\mathrm{h}_{\mathrm{IN}}{ }^{\mathrm{EC} 2}-\left(\mathrm{h}_{\mathrm{OUT}}{ }^{\mathrm{SC}}\right)^{\mathrm{LBS}}\right) /\left(\mathrm{h}_{\mathrm{OUT}}{ }^{\mathrm{EC} 2}-\mathrm{h}_{\mathrm{IN}}{ }^{\mathrm{EC} 2}\right), \mathrm{kg} / \mathrm{s},
$$

where $\mathrm{h}_{\mathrm{IN}}{ }^{\mathrm{EC} 2}$ - the enthalpy of the input to the low-pressure economizer, $\mathrm{kJ} / \mathrm{kg}$; $\mathrm{h}_{\mathrm{OUT}}{ }^{\mathrm{EC} 2}-$ the enthalpy of output to low-pressure economizer, $\mathrm{kJ} / \mathrm{kg}$.

Determined electric power of LPC:

$$
\mathrm{N}_{\mathrm{E}}^{\mathrm{LPC}}=\mathrm{D}_{0}^{\mathrm{LPC}} \cdot\left(\mathrm{h}_{0 \mathrm{LBS}}-\left(\mathrm{h}_{\mathrm{k}}^{\mathrm{LPC}}\right)^{\mathrm{LBS}}\right) \cdot \eta_{\mathrm{EM}} \cdot 10^{-3}, \mathrm{MW} .
$$

The total power gross of CCGT:

$$
\mathrm{N}_{\mathrm{E}}^{\mathrm{CCGT}}{ }_{\mathrm{GR}}=\mathrm{N}_{\mathrm{E}}^{\mathrm{GTU}}+\mathrm{N}_{\mathrm{E}}{ }^{\mathrm{HPC}}+\mathrm{N}_{\mathrm{E}}^{\mathrm{LPC}} \text {. }
$$

Net efficiency of CCGT trinary type with AC:

$$
\eta^{\mathrm{CCGT}}{ }_{\mathrm{NET}}=\left(\mathrm{N}_{\mathrm{E}}^{\mathrm{CCGT}}{ }_{\mathrm{GR}}-\mathrm{N}_{\mathrm{ON}}\right) \cdot 100 / \mathrm{Q}_{\mathrm{CC}}, \%,
$$

where $\mathrm{N}_{\mathrm{ON}}$ - electric power own needs, MW.

For to calculate the parameters of the burned fuel, combustion products, water and steam, and low-boiling substances are used the functions of the library REFPROP [8].

\section{Conclusion}

The proposed algorithm makes it possible to comprehensively calculate the combined operation of a CCGT of a trinary type and an air condenser. 
The use of a LBS in the lower Rankine cycle using air condenser allows wintertime reliably remove heat at low outdoor temperatures and low boiling substances and significantly raise the termal efficiency of the CCGT.

On the basis of the algorithm, a program was developed for the calculation of a CCGT with an air condenser in an Excel package, which makes it possible to carry out complex studies of the CCGT operation with changes in the outside air temperature.

\section{References}

1. S. Tsibulskiy, N. Galashov, A. Bannova, D. Melnikov, A. Kiselev, MATEC Web Conf. 141, 01025 (2017)

2. N. N. Galashov, S. A. Tsibulskii, Power Technology and Engineering 48, 459 (2015)

3. S. Tsibulskiy, N. Galashov, A. Bannova, D. Melnikov, A. Kiselev, MATEC Web Conf. 110, 01027 (2017)

4. A. G. Kostyuk, V. V. Frolov, A. E. Bulkin, A. D. Trukhny, Turbines of thermal and nuclear power plants: a textbook for high schools (Publishing house MEI, Moscow, 2001)

5. A. D. Trukhni, Steam and gas installations of power plants (Publishing house MEI, Moscow, 2013)

6. O. O. Milman, V. A. Fedorov, Air-condensing units (Publishing house MEI, Moscow, 2002)

7. K. Larionov, D. Gvozdjakov, A. Zenkov, V. Zaytsev, EPJ Web Conf. 110, 01034 (2016)

8. E. Lemmon, M. Huber, M. McLinden, REFPROP, standard reference database 23, version 8.0, National Institute of Standard and Technology (2007) 